\title{
In Vitro Antioxidant and Anti-inflammatory Potential Evaluations of Methanolic Extract of Acalypha hispida Burm.f. (Euphorbiaceae)
}

\author{
Akif Md Thousif and Md Shahidul Islam* \\ Department of Pharmacy, University of Science and Technology Chittagong (USTC), Bangladesh \\ *Corresponding author: Md Shahidul Islam, Department of Pharmacy, University of Science and Technology Chittagong (USTC) \\ Bangladesh.
}

To Cite This Article: Md Shahidul Islam, In Vitro Antioxidant and Anti-inflammatory Potential Evaluations of Methanolic Extract of Acalypha hispida Burm.f. (Euphorbiaceae). 2020 - 7(6). AJBSR.MS.ID.001211. DOI: 10.34297/AJBSR.2020.07.001211.

Received: 海 February 12, 2020; Published: 眥 March 05, 2020

\begin{abstract}
The principal goal of this research study is to evaluate the antioxidant and anti-inflammatory properties of traditional Bangladeshi medicinal extracts and to examine these activities in relation to their antioxidant content. Acalypha hispida Burm.f. (Euphorbiaceae) is a medicinal plant of Bangladesh and Indian subcontinent, which is widely used as folk medicine for the treatment of many diseases. The aim in the present study was to screen the phytochemical profile and pharmacological activities of methanolic extract of Acalypha hispida leaves. Because each part of Acalypha hispida Burm.f. has different constituents, the pharmacological effects of the plant vary according to the part of the plant evaluated. To investigate pharmacological activities DPPH scavenging assay and HRBC membrane stabilization methods were done for antioxidant and anti-inflammatory potential respectively. The phytochemical analysis of methanolic extract of plant leaves showed that they contained significant presence of flavonoids, phenols, saponins, terpenoids \& triterpenes. Alkaloids, glycosides \& tannins are also moderately present. Quantitative evaluations show significant presence of phenols than tannin content. The pharmacological studies revealed that the plant extracts may have significant antioxidant effect which is probably mediated by inhibition of DPPH free radical, which is responsible for oxidation. The IC50 values by DPPH scavenging assay observed for standard \& leaves were $96.37 \mu \mathrm{g} / \mathrm{ml} \& 493.46 \mu \mathrm{g} / \mathrm{ml}$ respectively. There is also moderate anti-inflammatory activity. The IC50 values for anti-inflammatory activity by standard \& leaves were $25.03 \mu \mathrm{g} / \mathrm{ml} \& 843.05 \mu \mathrm{g} / \mathrm{ml}$ respectively.
\end{abstract}

Keywords: Acalypha hispida; Phenols; Tannin content; Antioxidant; Anti-inflammatory; $\mathrm{IC}_{50}$ values

\section{Introduction}

From the very beginning of the civilization, people have depended on nature for their fundamental needs, for the making of diet, housing, wear, nourishments, flavors and drugs. Many plants have made the source of refined traditional drug systems that have been in being for thousands of years and remain to deliver human with new medications. So, medicinal plant treatment is based on results of hundreds and maybe thousands of years of use. Acalypha hispida Burm.f. (Euphorbiaceae) is locally recognized as sibjota or jotamangshi in Bangladesh. It is also known as shibjhul in Bengali. This one produces in the coastal areas of Bangladesh [1]. Many parts of the plant are used in infectious diarrhoea, pulmonary problems, and in asthma [2]. In Egypt, bishop's weed (Ammi majus) was stated to be used to treat vitiligo, a skin condition categorized by a loss of pigmentation [3]. More recently, a drug (methoxypsoralen) has been produced from this plant to treat psoriasis and other skin disorders, as well as T-cell lymphoma [4]. Alternative medicine demanded to have the healing properties of medicine, but which are contradicted, unproven, or are excessively destructive in relation to their effect [5]. Alternative treatments or identifies are not part of drug or science-based healthcare systems [6]. So, alternative drug consists of a wide diversity of practices, products, and therapies ranging from those that are naturally reasonable and to those with known injurious and toxic properties [7]. Cassia siamea (Lam.) is an extensive medicinal and food plant cultured in Southeast Asia and sub-Saharan Africa. Many traditional claims are stated as medical actions on numerous diseases like constipation, malaria and fevers and jaundice [8]. Moreover, aerial portions of C. siamea are beneficial in ringworm and connected skin diseases [9]. Ethno-botanical 
examinations also advise antinociceptive and antiviral activities of aerial parts of C. siamea antioxidant and antihypertensive action. Moreover,a laxative activity, sedative activity and anti-inflammatory of stem bark extract of C. siamea were also stated [10]. Such type actions can be due to the presence of barakol, which has anxiolytic and CNS inhibitory properties.

\section{Materials and Methods}

\section{Plant Material}

For this research work, the leaves of A. hispida was collected during July 2018 from the University campus of University OF Chittagong, Bangladesh.

\section{Determination of Total Phenolic Content (TPC)}

As it is known that in the alkaline condition phenols ionize absolutely. While Folin-Ciocalteu's reagent is used in this ionized phenolic solution, the reagent will freely oxidize the phenols. Usual color of Folin-Ciocalteu's reagent is yellow and after the oxidation process the solution converts blue. The strength of the color alteration is restrained in a spectrophotometer at $760 \mathrm{~nm}$. The absorbance value will imitate the total phenolic content of the compound [11].

\section{Method of Sample Preparation}

In this research work, the total phenolics of the extracts were evaluated using the Folin and Ciocalteu reagent, following the method designated with slight alterations [12]. The test sample
$(0.2 \mathrm{~mL})$ was variegated with $0.6 \mathrm{~mL}$ of water and $0.2 \mathrm{~mL}$ of Folin-Ciocalteu's phenol reagent (1: 1). Subsequently, $5 \mathrm{~min}, 1 \mathrm{~mL}$ of saturated sodium carbonate solution $(8 \% \mathrm{w} / \mathrm{v}$ in water) was added to the mixture and the volume was completed up to $3 \mathrm{~mL}$ with distilled water. Then the reaction was preserved in the dark for $30 \mathrm{~min}$ and after centrifuging the absorbance of blue color from dissimilar samples was restrained at $760 \mathrm{~nm}$. All determinations were carried out in triplicate [13].

\section{Method of Sample Preparation}

In this research work, fifty micro liters $(\mu \mathrm{l})$ of tannins extract for each sample was occupied in test tube and volume was completed to $1.0 \mathrm{ml}$ with distilled water. Then, $0.5 \mathrm{ml}$ Folin Ciocalteu reagent was added and varied accurately. Then $2.5 \mathrm{ml} 20$ per cent sodium carbonate solution was added and varied accurately and kept for 40 minutes at room temperature. Moreover,the optical density was reserved at $725 \mathrm{~nm}$ in UV spectrophotometer and concentration was assessed [14].

\section{Results and Discussion}

\section{Phytochemical Screening}

In Table 1-3, it is shown that different chemical constituents such as alkaloids, flavonoids, glycosides, phenols, saponins, tannins, terpenoids and triterpenes was present in an Acalypha hispida. And are clearly accountable for its different therapeutic and pharmacological actions (Tables 1-3).

Table 1: Total phenolic content (TPC) of Acalypha hispida.

\begin{tabular}{|c|c|c|c|c|}
\hline Test sample & Absorbance & TPC (mg of GAE $/ \mathbf{g})$ & Average & TPC (mg of GAE/g) \pm SEM \\
\hline & 0.304 & 27.31 & & \\
\hline Leaves & 0.312 & 26.47 & 26.73 & $26.73 \pm 0.4$ \\
\hline
\end{tabular}

Note: Total phenolic content (TPC) observed for leaves of Acalypha hispida was $26.73 \pm 0.4 \mathrm{mg}$ of GAE/g.

Table 2: Total tannin content (TTC).

\begin{tabular}{|c|c|c|c|c|}
\hline Test sample & Absorbance & TTC (mg of TAE/g) & Average & \\
\hline & 0.301 & 1.77 & 1.787 \\
\hline Leaves & 0.299 & 1.802 & & \\
\end{tabular}

Note: Total tannin content (TTC) observed for leaf of Acalypha hispida was $1.787 \pm 0.016 \mathrm{mg}$ of TAE/g.

Table 3: Different chemical compositions resent in plants.

\begin{tabular}{|c|c|c|}
\hline Secondary Metabolites & Name of the Test \\
\hline Alkaloids & Wagner test \\
\hline Flavonoids & Specific test \\
\hline Glycosides & General test \\
\hline Phenols & Litmus test \\
\hline Saponins & Froth test \\
\hline
\end{tabular}




\begin{tabular}{|c|c|c|}
\hline Tannins & Ferric chloride test & ++ \\
\hline Terpenoids & General test & ++ \\
\hline Triterpenes & Salkowski's test & ++ \\
\hline
\end{tabular}

\section{Anti-inflammatory Activity}

Percent inhibition of protein denaturation was calculated as follows [15]:

$\%$ inhibition $=\frac{\text { Control-Sample }}{\text { Control }} \times 100$

Table 4: Average absorbance of control.

\begin{tabular}{|c|c|c|}
\hline & Absorbance \\
\hline & 0.367 & 0.36 \\
\hline Control & 0.3656 & 0.3656 \\
\hline
\end{tabular}

Table 5: Spectroscopic Determination of Anti-inflammatory Activity of Leaves.

\begin{tabular}{|c|c|c|c|c|c|}
\hline Concentration $(\boldsymbol{\mu g} / \mathbf{m l})$ & Absorbance & \% Inhibition & Average & \% Inhibition \pm SEM & $\mathbf{I C}_{\mathbf{5 0}}(\boldsymbol{\mu g} / \mathbf{m l})$ \\
\hline 125 & 0.438 & 1.42 & 1.4 & $1.40 \pm 0.7$ & \\
\hline & 0.436 & 0.8 & & & $10.99 \pm 0.3$ \\
\hline & 0.434 & 1.99 & & & 843.05 \\
\hline & 0.4 & 10.12 & 10.99 & & $47.46 \pm 0.6$ \\
\hline & 0.399 & 11.04 & & & \\
\hline & 0.402 & 47.04 & 47.46 & & \\
\hline & 0.351 & 48.89 & & & $54.67 \pm 0.4$ \\
\hline
\end{tabular}

Table 6: Spectroscopic Determination of Anti-inflammatory Activity of Standard Compound (Diclofenac- $\mathrm{Na}$ ).

Concentration $(\mu \mathrm{g} / \mathrm{ml})$

125

250

500

1000

\begin{tabular}{|c|c|}
\hline Absorbance & \% Inhibition \\
0.344 & 47.09 \\
0.341 & 47.1 \\
0.34 & 48.01 \\
0.239 & 65.67 \\
0.24 & 66.35 \\
0.237 & 67.33 \\
0.125 & 79.87 \\
0.12 & 80.25 \\
0.121 & 79.1 \\
0.073 & 89.78 \\
0.074 & 90.08 \\
0.076 & 91.07 \\
\hline
\end{tabular}

Average
47.5
66.45
79.95
90.28

\% Inhibition \pm SEM
$81.67 \pm 0.4$
$87.57 \pm 0.5$
$92.68 \pm 0.4$
$96.50 \pm 0.4$

IC50 $(\mu \mathrm{g} / \mathrm{ml})$ 
Table 7: Comparative study based on $\mathrm{IC}_{50}$.

\begin{tabular}{|c|c|}
\hline Test Sample & IC $_{50}$ \\
\hline Leaves & 843.05 \\
\hline Standard & 25.03 \\
\hline
\end{tabular}

In this research work, the method of HRBC membrane stabilization was selected to estimate anti-inflammatory activities (Tables 4-7).

In this research work, it exposed that the plant extracts might have moderate anti-inflammatory effect which is possibly reconciled by HRBC membrane stabilization.

\section{Antioxidant activity}

Here, the free radical-scavenging action of extracts was assessed with the DPPH assay [16]. In this research work, it exposed that the plant extracts may have important antioxidant effect which is maybe reconciled by inhibition of DPPH free radical, which is accountable for oxidation (Tables 8-11).

Table 8: Average absorbance of control.

\begin{tabular}{|c|c|c|}
\hline & Absorbance & Average \\
\hline & 0.914 & 0.92 \\
\hline Control & 0.916 & \\
\hline
\end{tabular}

Table 9: Spectroscopic Determination of Antioxidant Activity of Leaves.

\begin{tabular}{|c|c|c|c|c|c|}
\hline Concentration $(\mu \mathrm{g} / \mathrm{ml})$ & Absorbance & $\%$ SCV & Average & $\%$ SCV \pm SEM & IC50 $(\mu \mathrm{g} / \mathrm{ml})$ \\
\hline \multirow{3}{*}{62.5} & 0.962 & 11.67 & \multirow{3}{*}{11.9} & \multirow{3}{*}{$8.78 \pm 0.5$} & \\
\hline & 0.956 & 11.99 & & & \\
\hline & 0.951 & 12.06 & & & \\
\hline \multirow{3}{*}{125} & 0.756 & 26.9 & \multirow{3}{*}{26.88} & \multirow{3}{*}{$23.02 \pm 0.4$} & \\
\hline & 0.75 & 26.68 & & & \\
\hline & 0.751 & 27.04 & & & \\
\hline \multirow{3}{*}{250} & 0.515 & 53.97 & \multirow{3}{*}{53.98} & \multirow{3}{*}{$53.98 \pm 0.5$} & \multirow{3}{*}{493.46} \\
\hline & 0.51 & 54.86 & & & \\
\hline & 0.511 & 53.05 & & & \\
\hline \multirow{3}{*}{500} & 0.314 & 69.6 & \multirow{3}{*}{69.07} & \multirow{3}{*}{$69.07 \pm 0.6$} & \\
\hline & 0.31 & 68.19 & & & \\
\hline & 0.311 & 69.38 & & & \\
\hline \multirow{3}{*}{1000} & 0.115 & 89.97 & \multirow{3}{*}{90.52} & \multirow{3}{*}{$90.49 \pm 06$} & \\
\hline & 0.098 & 90.89 & & & \\
\hline & 0.098 & 90.66 & & & \\
\hline \multirow{3}{*}{2000} & 0.085 & 98.57 & \multirow{3}{*}{98.6} & \multirow{3}{*}{$98.6 \pm 0.5$} & \\
\hline & 0.089 & 97.99 & & & \\
\hline & 0.087 & 99.17 & & & \\
\hline
\end{tabular}

Table 10: Spectroscopic Determination of Antioxidant Activity of Standard Compound (L- Ascorbic Acid).

\begin{tabular}{|c|c|c|c|c|c|}
\hline Concentration $(\mu \mathrm{g} / \mathrm{ml})$ & Absorbance & $\%$ SCV & Average & $\%$ SCV \pm SEM & IC50 $(\mu \mathrm{g} / \mathrm{ml})$ \\
\hline \multirow{3}{*}{62.5} & 0.35 & 61.53 & \multirow{3}{*}{61.86} & \multirow{3}{*}{$61.86 \pm 0.4$} & \\
\hline & 0.351 & 61.49 & & & \\
\hline & 0.349 & 62.56 & & & \\
\hline \multirow{3}{*}{125} & 0.26 & 71.37 & \multirow{3}{*}{70.79} & \multirow{3}{*}{$70.79 \pm 0.36$} & \\
\hline & 0.268 & 70.12 & & & \\
\hline & 0.267 & 70.89 & & & \\
\hline
\end{tabular}




\begin{tabular}{|c|c|c|c|c|c|}
\hline \multirow{3}{*}{250} & 0.196 & 78.27 & \multirow{3}{*}{78.87} & \multirow{3}{*}{$78.87 \pm 0.50$} & \multirow{3}{*}{96.37} \\
\hline & 0.188 & 79.84 & & & \\
\hline & 0.195 & 78.52 & & & \\
\hline \multirow{3}{*}{500} & 0.118 & 86.78 & \multirow{3}{*}{87.27} & \multirow{3}{*}{$87.27 \pm 0.30$} & \\
\hline & 0.119 & 87.39 & & & \\
\hline & 0.119 & 87.65 & & & \\
\hline \multirow{3}{*}{1000} & 0.047 & 94.6 & \multirow{3}{*}{94.49} & \multirow{3}{*}{$94.49 \pm 0.2$} & \\
\hline & 0.056 & 94.28 & & & \\
\hline & 0.045 & 94.59 & & & \\
\hline \multirow{3}{*}{2000} & 0.029 & 97.65 & \multirow{3}{*}{96.92} & \multirow{3}{*}{$96.92 \pm 0.6$} & \\
\hline & 0.03 & 97.24 & & & \\
\hline & 0.033 & 95.89 & & & \\
\hline
\end{tabular}

Table 11: Comparative study based on IC50.

\begin{tabular}{|c|c|}
\hline Test Sample & IC $_{50}$ \\
\hline Leaves & 491.15 \\
\hline Standard & 96.37 \\
\hline
\end{tabular}

In this research work, it exposed that the plant extracts may have important antioxidant effect which is maybe reconciled by inhibition of DPPH free radical.

\section{Conclusion}

In this research work it was observed that qualitative assessments indication weighty existence of flavonoids, phenols, saponins, terpenoids and triterpenes. It was also observed that alkaloids, glycosides and tannins are moderately present. Quantitative assessments show weighty presence of phenols than tannin content. There is an excellent antioxidant activity in the methanolic extract. There was also moderate anti-inflammatory activity in the methanolic extract of leaves. Each part of Acalypha hispida has altered constituents, the pharmacological properties of the plant differ in relation to the part of the plant assessed. Quantitative assessments show weighty existence of phenols than tannin content. The IC50 values by DPPH scavenging evaluate observed for standard and leaves were $96.37 \mu \mathrm{g} / \mathrm{ml}$ and $493.46 \mu \mathrm{g} / \mathrm{ml}$ separately. Thus, there is a tremendous antioxidant activity in the methanolic extract. Moreover, there was also moderate anti-inflammatory activity in the methanolic extract of leaves. So, it is evaluated that the IC50 values for anti-inflammatory action by standard and plant leaves were $25.03 \mu \mathrm{g} / \mathrm{ml}$ and $843.05 \mu \mathrm{g} / \mathrm{ml}$ separately.

\section{References}

1. Meyer S (1982) Phytochemical methods A guide to modern techniques of plant analysis. Champan and Hall, USA.

2. Seebaluck R, Gurib Fakim A, Mahomoodally F (2015) Medicinal plants from the genus Acalypha (Euphorbiaceae)--a review of their ethnopharmacology and phytochemistry. J Ethnopharmacol 159: 137157.

3. Cragg GM, Newman DJ (2005) Biodiversity: A continuing source of novel drug leads. Pure Appl Chem 77(1): 7-24.
4. Heinrich M, Barnes J, Gibbons S, Williamson EM (2004) Fundamentals of Pharmacognosy and Phytotherapy. Churchill Livingstone, Elsevier Science Ltd, UK.

5. Staniszewska I, Królicka A, Malinski E, Łojkowska E, Szafranek J (2003) Elicitation of secondary metabolites in in vitro cultures of Ammi majus L. Enzymes Microb Technol 33(5): 565-568.

6. Beissert S, Schwarz T (2002) Role of immunomodulation in diseases responsive to phototherapy. Methods 28(1): 138-144.

7. Ng T, Liu F, Lu Y, Cheng C, Wang Z (2003) Antioxidant activity of compounds from the medicinal herb Aster tataricus. Comp Biochem Physiol C Toxicol Pharmacol 136(2): 109-115.

8. Newman DJ, Cragg GM, Snader KM (2000) The influence of natural products upon drug discovery. Nat Prod Rep 17(3): 215-234.

9. GF Nsonde Ntandou, JT Banzouzi, B Mbatchia, RDG Elion Itou, AW Etou Ossibi, et al. (2010) Analgesic and anti-inflammatory effects of Cassia siamea Lam. Stem bark extracts. J Ethnopharmacol 127(1): 108-111.

10. G Kaur, M Alam, Z Jabbar, K Javed, M Athar (2006) Evaluation of antioxidant activity of Cassia siamea flowers. J Ethnopharmacol 108(3): 340-348.

11. Balunas M J, Kinghorn DA (2005) Drug discovery from medicinal plants. Review article. Life Sc 78(5): 431-441.

12. Ahmad Billal, Naeem A Khan, A Ghufran, I Inamuddin (2005) Pharmalogical Investigation of Cassia sophera, Linn. var. purpurea Roxb. Med J Islamic World Acad Sci 15(3): 105-109.

13. Braca A, Tommasi ND, Bari LD, Pizza C, Politi M, et al. (2001) Antioxidant principles from Bauhinia terapotensis. J Nat Prod 64(7): 892-895.

14. Schulze J, Raasch W, Siegers CP (2003) Toxicity of Kava pyrones, drugs safety and precautions-a case study. Phytomedicine 10(4): 68-73.

15. Mazumder ME, Rahman HS (2008) Pharmocological evaluationof Bangladeshi medicinal plants for antioxidant activity. Pharm Biol 46(10): 704-709.

16. Willams BC, Saju RM (2016) Micropropagation, phytochemical screening and antioxidant potential of a wild epiphytic orchid Acampe praemorsa (Roxb.) of Kanyakumari District, India. Eur J Pharm Med Res 3(5): 572576. 